\title{
KERAGAMAN PROTISTA DI HUTAN MANGROVE SEBAGAI SUMBER BELAJAR MAHASISIWA PENDIDIKAN BIOLOGI UNIVERSITAS BORNEO TARAKAN
}

\section{Diversity of Protist in Mangrove Forest as Learning Resorurces of Biology Education Students Universitas Borneo Tarakan}

\author{
Fitri Wijarini ${ }^{\mathrm{a}^{*}}$, Nursia $^{\mathrm{a}}$ Listiani $^{\mathrm{a}}$
}

aJurusan Pendidikan Biologi/Fakultas Keguruan dan Ilmu Pendidikan/Universitas Borneo Tarkan, Tarkan, Kalimantan Utara, Indonesia ${ }^{*}$ Corresponding author: Jl. Amal Lama, Tarakan Timur, Tarakan, Kalimantan Utara, 77123, Indonesia. E-mail: fitriwijarini2@gmail.com

\begin{abstract}
Abstrak
Penelitian ini bertujuan untuk mengetahui keragaman Protista di hutan mangrove . pengambilan sampel dilakukan di keempat titik/plot yaitu plot A, B, C, dan D dimana masingmasing diukur sejauh 5 meter kedalam. Masing-masing Plot diberi perlakuan dengan diberikan rendaman jerami, diberikan rendaman serasah daun dan tidak diberi perlakuan. Hasil penelitian menunujukkan bahwa sebagain besar Protista yang ditemukan adalah Protista mirip hewan atau protozoa. Untuk Protista mirip alga hanya alga clorophyta yang ditemukan sedangkan alga mirip jamur tidak ditemukan. Keragaman protozoa yang ditemukan berasal dari kelas ciliate. Keragaman Protista hasil penelitian di hutan mangrove dapat digunakan sebagai sumber belajar mahasiswa penempuh mata kuliah Protista. Pemanfaatan keragaman Protista sebagai sumber belajar memberikan pengalaman yang nyata bagi mahasiswa .
\end{abstract}

Kata kunci

Keragaman Protista, Sumber belajar

Abstract

The aim of this research is to know of biodiversity of protest in Mangrove Forest. The sample collection was collected in 4 plots consist of plot A, plot B, plot $C$, and plot $D$, where the plot was measured 5 meter to down. Each plots was treated by leaf litter, and the other plot was not given a treatment. The result showed the majority of Protista that was collected was Protozoa. The Protista like algae is found chlorophyta, while algae which is like fungi is not found. The diversity of protozoa that found is ciliate. The research result of mangrove forest can be used as learning resources for students who programed Protista subject. The using of this learning resources is giving real experience to students.

Keywords

Protista diversity, Learning resources 


\section{Pendahuluan}

Protista merupakan mikroorganisme bersifat eukariotik (memiliki membrane inti) dan bersifat autorof atau heterotrop. Mikroorganisme ini dapat bersifat uniseluler ataupun multiseluler. Protista uniseluler berukuran 5 mikrimeter sd $3 \mathrm{~mm}$ sedangkan Protista multiseluler berukuran $0.01 \mathrm{~mm}$ sd 65 meter. Keberadaan Protista sebagai organisme autotroph berperan sebagai fitoplankton, dan mampu menghasilkan oksigen di bumi. Selain itu manfaat lain dari mikroorganisme Protista yaitu sebagai produsen dann konsumen dalam rantai makanan, dan berperan penting dalanm siklus karbon.

Protista dikelompokkan menjadi tiga kelompok yakni Protista mirip hewan (protozoa), Protista mirip tumbuhan (Alga), dan Protista mirip jamur. Protista mirip hewan terdiri dari kelas rhizopoda, kelas ciliate, kelas flagellate, dan kelas sporozoa. Dasar pengelompokan pada protozoa selain berdasarkan alat geraknya juga berdasarkan reproduksi baik secara seksual atau aseksual. Kelas Rhizopoda bergerak dengan menggunakan kaki semu, cilliata bergerak dengan cilia, flagellate bergerak dengan flagell, dan sporozo tidak memiliki alat gerak.Protista mirip tumbuhan (alga) dikelompokkan menjadi empat kelas, yaitu rhodophyta (alga merah), clorophyta (alga hijau), crysophyta(alga coklat), dan phaeophyta (alga pirang). Dasar pengelompokkan alga mirip tumbuhan berrdasarkan pada pigmen tambahan, struktur kloroplas, susunan kimia dinding sel, dan cadangan makanan yang dihasilkan. Protista mirip jamur dikelompokkan menjadi tiga yakni oomicota (jamur air), myxomicota (jamur lendir), dan jamur lender seluler (Acrasiomycota). Protista mirip jamur memiliki kesamaan dengan jamur yaitu menghasilkan spora, bersifat heterotroph serta bersifat parasite atau bersifata pengurai.

Habitat Protozoa menyebar luas dan banyak ditemukan di perairan tawar, air laut, air payau, kolam dan ada juga yang hidup di dalam tubuh organisme multiseluler. Air payau menjadi salah satu tempat hidup berbagai Protozoa. Populasi Protozoa di air payau lebih tinggi dari pada di sungai karena kondisi payau yang cenderung lebih stabil dalam hal suhu, instensitas cahaya, tekanan air, besarnya arus, dan ketersediaan makanan. Salah satu payau yang memiliki karakter tersebut adalah Kawasan Konservasi Hutan Mangrove Dan Bekantan Kota Tarakan.

Tujuan penelitian ini adalah untuk mengetahui keragaman Protista di Hutan Mangrove yang juga merupakan Objek wisata Kota Tarakan. Manfaat yang dapat diperoleh dari penelitian berupa sumbangan informasi mengenai keberagaman spesies filum protista di Objek Wisata Kawasan Konservasi Hutan Mangrove Dan Bekantan Kota Tarakan sehingga dapat digunakan sebagai sumber belajar mata kuliah Protista bagi mahasiswa Pendidikan Biologi Universitas Borneo Tarakan. Adapun tindak lanjut dari penelitian ini adalah adanya pengembangan bahan ajar berupa modul Protista yang akan digunakan oleh mahasiswa yang menempuh mata kuliah Protista. 


\section{Material dan metode}

Penelitian ini dilakukan di Kawasan Konservasi Mangrove dan Bekantan (KKMB) kota Tarakan dan di Laboratorium IPA lantai 2 gedung Fakultas Keguruan dan Ilmu Pendidikan (FKIP) Universitas Borneo Tarakan . Pada hari Rabu, 03 Juli 2019. Pengambilan sampel penelitian pada hari Sabtu, 29 Juni 2019 di kawasan hutan mangrove Kota Tarakan. Sampel yang diambil berupa air yang tergenang di hutan mangrove pada keadaan air surut. Sampel diambil dari 4 plot dan ditandai diberi label sampel A, B, C dan D. Semua sampel diambil dengan cara mengukur 5 meter ke dalam hutan mangrove dan diambil dari sisi depan, sisi kiri, sisi kanan, dan sisi belakang hutan mangrove.

Semua sampel A, B, C dan D masing-masing diberikan 3 perlakuan yang berbeda, yaitu: 1. Sampel air dikawasan hutan mangrove yang direndam dengan serasah daun mangrove \pm 4 hari, 2. Sampel air dikawasan hutan mangrove yang direndam dengan jerami \pm 4 hari, 3. Sampel air dikawasan hutan mangrove tanpa diberi perlakuan apapun. Sehingga jumlah total sampel yang akan diamati sebanyak 12 sampel. Selama waktu perendaman wadah tempat sampel tersebut dibiarkan terbuka dan tidak boleh tertutup. Sampel A, B, C dan D yang sudah diberi perlakuan kemudian diamati di Laboratorium IPA Lantai 2 FKIP.

Alat yang digunakan dalam penelitian ini yaitu mikroskop, pipet tetes, gelas ukur, kaca preparat, cover glass. Bahan yang digunakan adalah air mangrove, jerami, serasah daun dan tisu. Prosedur kerja yang dilakukan dalam penelitian ini yaitu mempersiapkan semua alat dan bahan yang digunakan, menyiapkan 12 gelas ukur yang masing-masing diberi sampel penelitian. Mengambil sampel penelitian dengan menggunakan pipet tetes kemudian meletakkan sampel di kaca preparat, metutup dengan menggunakan kaca penutup lalu mengamati sempel dibawah mikroskop.

\section{Hasil dan Diskusi}

Berdasarkan hasil penilitian diperoleh bahwa sebagian besar Protista yang ditemukan adalah Protista dari filum ciliate. Sampel penelitian berasal dari keempat plot yaitu plot A, plot B, plot $\mathrm{C}$, dan plot $\mathrm{D}$. Masing-masing sampel diberi perlakuan dengan ditambahkan rendaman jerami, ditambahkan rendaman serasah daun, dan tanpa diberikan rendaman apapun. Penghitungan jumlah Protista dihitung berapa banyak jumlah Protista yang ditemukan pada saat pengamatan. Hasil penelitian tentang pengamatan protista di hutan mangrove kawasan konservasi Bekantan dan Hutan mangrove disajikan pada tabel1. 


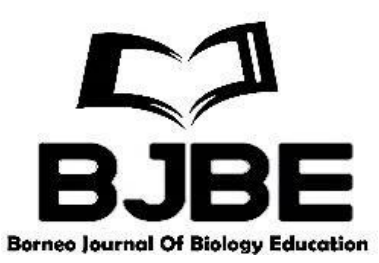

Plot A

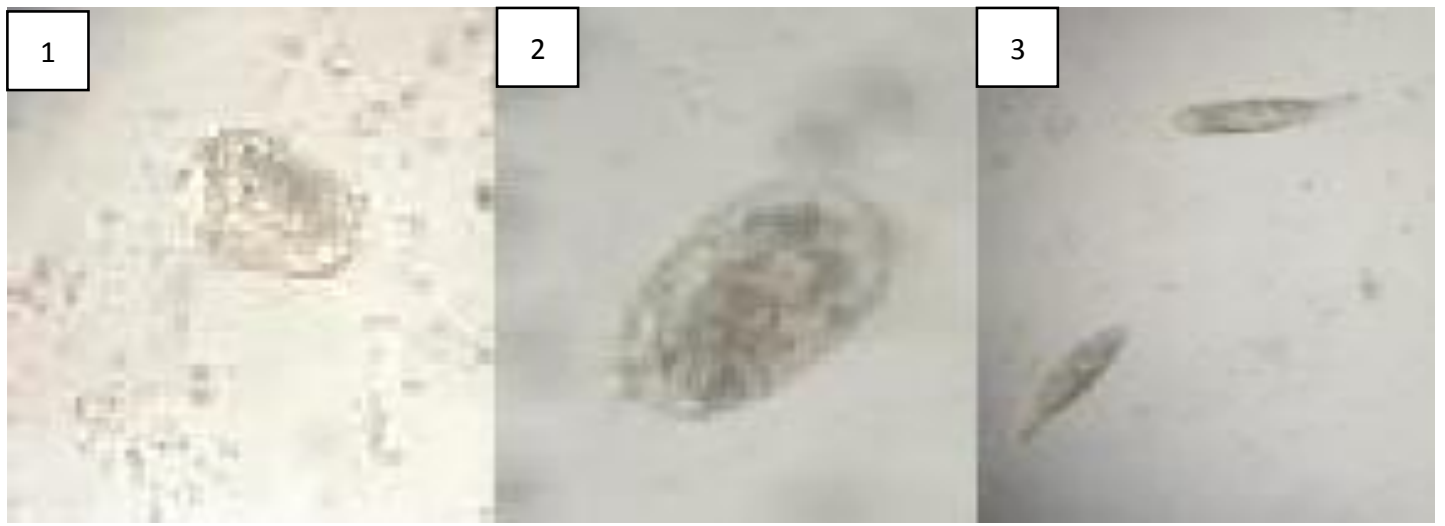

Plot B
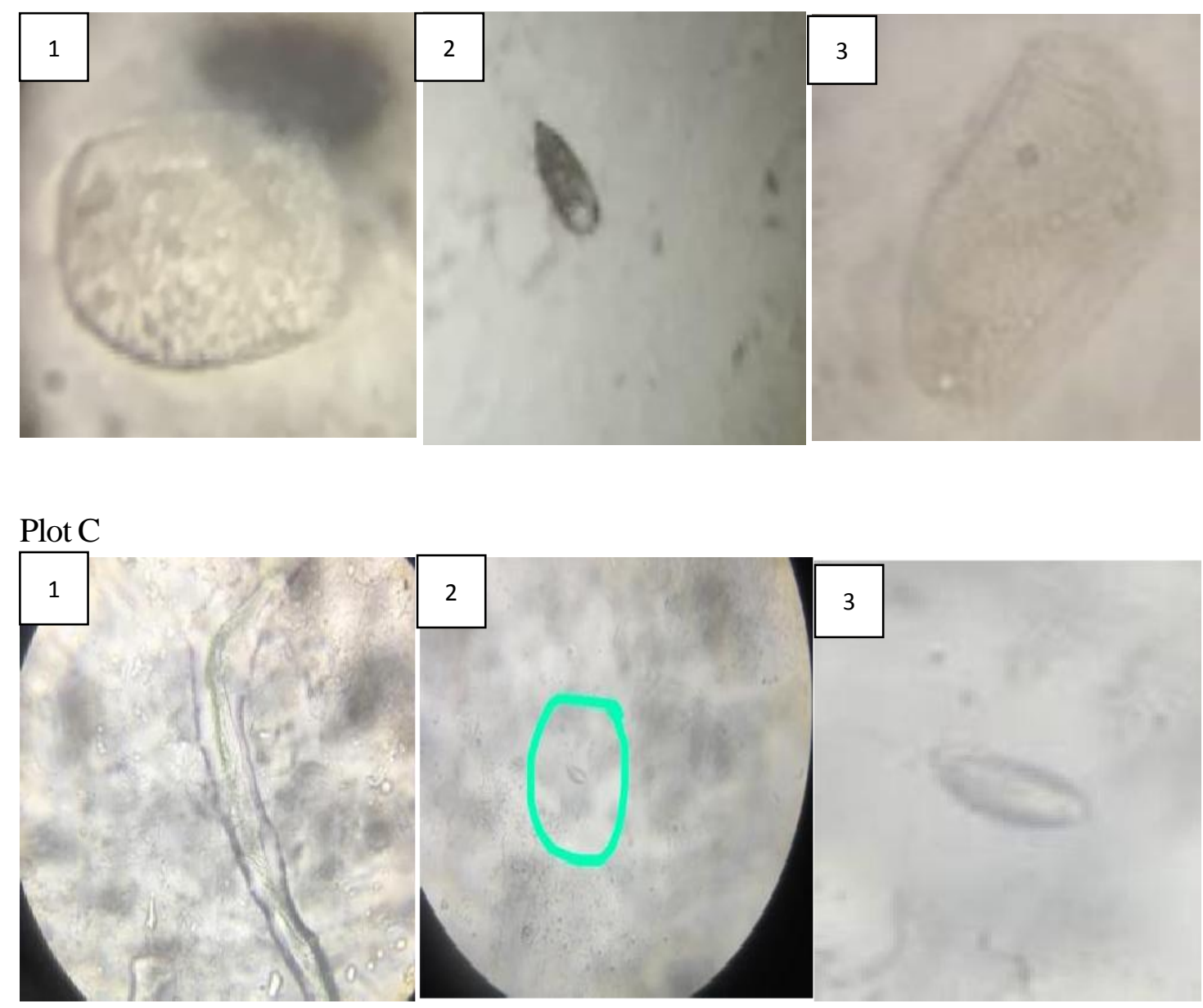


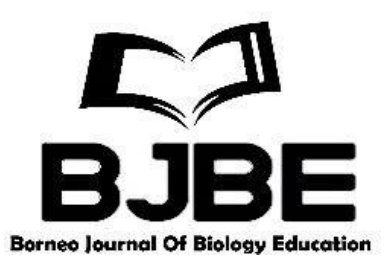

Plot D

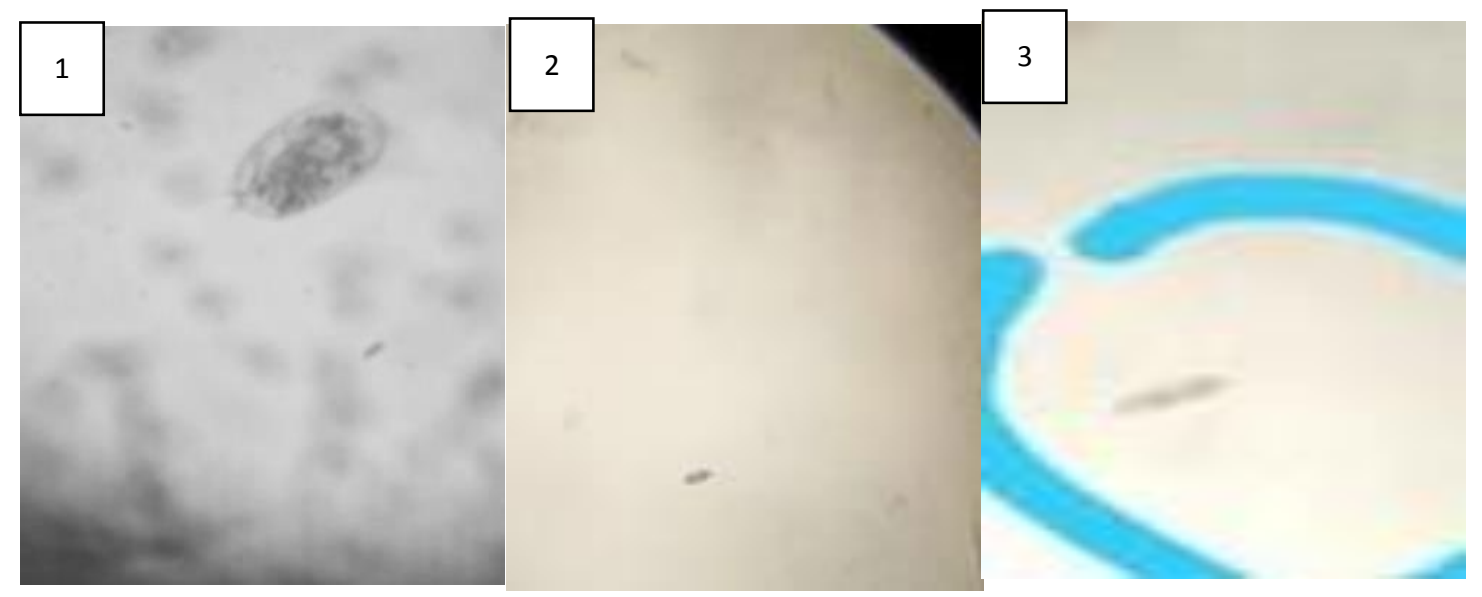

Gambar 1. Plot A 1). Calpoda sp, 2). Ciliophora sp terdapat pada rendaman jerami 3). Euglena viridis terdapat pada serasah daun. Plot B 1). Paramecium sp 2). Euglena sp 3). Paramecium sp. Plot C 1). Chlorophyta 2). Stylonichia sp 3). Flagellata terdapat pada serasah daun. Plot D 1). Ciliata terdapat pada air mangrove 2). Paramecium sp terdapat pada rendaman jerami 3). Flagellata dan cilliata terdapat pada serasah daun.

Perlakuan dengan memberikan jerami dan serasah daun pada sampel bertujuan untuk memberikan nutrisi bagi Protista khususnya protozoa, dengan adanya penambahan nutrisi diharapkan populasi Protista dalam sample dapat meningkat. Namun berdasarkan hasil penelitian yang telah dilakukan didapatkan bahwa populasi Protista pada sample yang tidak diberi perlakuan baik jerami ataupun serasah daun juga ditemukan jumlah Protista yang cukup banyak. Hal ini disebabkan karena sifat air di hutan mangrove bersifat payau dimana kondisi air payau cenderung lebih stabil dalam hal suhu, instensitas cahaya, tekanan air, besarnya arus, dan ketersediaan makanan. Sehingga meskipun tidak diberi jerami dan serasah daun populasi Protista dalam sampel penilitian tetap tinggi.

\section{Keragaman Protista sebagai sumber belajar mata kuliah Protista}

Dari hasil penelitian yang telah dilakukan tentang keragaman Protista di hutan mangrove ditemukan berbagai jenis Protista yang dapat dijadikan sebagai alternative sumber belajar bagi mahasiswa yang menempuh mata kuliah Protista. Pemanfaatan lingkungan alam sekitar sebagai sumber belajar dapat membangkitkan dan memotivasi siswa dalam belajar biologi (Kasrina et all, 2012). Pemanfaatan hasil penelitian Protista memberikan pengalaman belajar ke mahasiswa dengan mengamati secara langsung keragaman jenis Protista yang ditemukan di lingkungan sekitar. Sebagai sumber belajar hasilpenelitian ini dapat memberikan gambaran secara nyata bagaiman bentuk, pergerakan dan karakteristik dari masing-masing spesies.

\section{Kesimpulan}

Berdasarkan hasil penelitian didapatkan kesimpulan bahwa keragaman Protista yang banyak ditemukan di Kawasan Konservasi hutan Mangrove adalah protozoa yakni kelas ciliate dan flagellate. Sedangkang Protista mirip tumbuhan hanya ditemukan clorophyta 


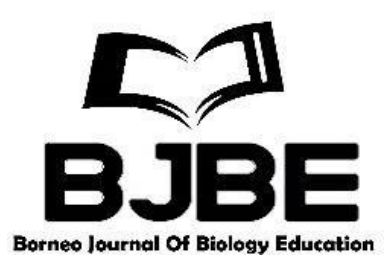

dengan jumlah 1. Pemnafaatan keragaman Protista sebagai bahan ajar adalah dengan memberikan pengalaman secara langsung bagaiman bentuk dan karakteristik Protista.

\section{Daftar Pustaka}

Afif., Jamaludin, Ngabekti, Sri, Pribadi., Tyas Agung. (2014). Keanekaragaman Makrozoobentos sebagai Indikator Kualitas Perairan Di Ekosisitem Mangrove Wilayah Tapak Kelurahan Tugurejo Kota Semarang.Unnes Journal Of Life Science 3(1):47-52.ISSN 2252-6277.

Astuti., Widi, Jamali., Adil, Amin.,Muhammad. (2007). Desalinasi Air Payau Menggunakan Surfactant Modified Zeolite (SMZ). Jurnal Zeolit Indonesia Vol.6:32-37.

Hariyani.,Devi, Slamet., Adeng, Santri., Didi Jaya. (2017). Jenis-jenis Protista di Danau Teluk Gelam Kabupaten OKI Provinsi Sumatera Selatan. Jurnal Pembelajaran Biologi vol 5. No.2:126-136.

Junda,. Muhammad, Hijriah, Hala., Yusminah. (2013). Identifikasi Perifiton Sebagai PEnentu Kualitas Air Pada Tambak Ikan Nila. Jurnal Bionature Vol. 14: 16-24.

Kasrina,Irawati., Sri, Jayanti., Wahyu E. (2012). Ragam Jenis Mikroalga di Air Rawa Kelurahan Bentiring Permai Kota Bengkulu Sebagai Alternatif Sumber Belajar Biologi SMA. Jurnal Exacta: Vol.X No.1: 36-41. ISSN 1412-3617.

Maresi.,Sinta R.P., Priyanti, Yunita., Etyn. (2105). Fitoplankton Sebagai BioIndikator Saprobitas Perairan Di Situ Bulakan Kota Tangerang. Al-Kauniyah Jurnal Biologi Vol.8 No. 2.

Nirmalasari, Ridha. (2018). Analisis Kualitas Air Sungai Sebangau Pelabuhan Kereng Bengkiray Berdasarkan Keanekaragaman dan Komposisi Sitoplankton. Jurnal Ilmu Alam dan Lingkungan Vol 9 No.17: 48-58. 